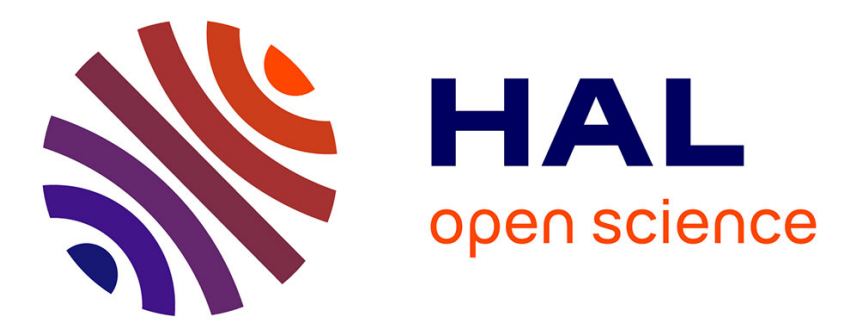

\title{
Noninvasive vascular occlusion with HIFU for venous insufficiency treatment: preclinical feasibility experience in rabbits
}

\author{
N Barnat, A Grisey, B Lecuelle, J. Anquez, B Gerold, S. Yon, J.-F Aubry
}

\section{- To cite this version:}

N Barnat, A Grisey, B Lecuelle, J. Anquez, B Gerold, et al.. Noninvasive vascular occlusion with HIFU for venous insufficiency treatment: preclinical feasibility experience in rabbits. Physics in Medicine and Biology, 2019, 64 (2), pp.025003. 10.1088/1361-6560/aaf58d . hal-02403722

\section{HAL Id: hal-02403722 \\ https://hal.science/hal-02403722}

Submitted on 11 Dec 2019

HAL is a multi-disciplinary open access archive for the deposit and dissemination of scientific research documents, whether they are published or not. The documents may come from teaching and research institutions in France or abroad, or from public or private research centers.
L'archive ouverte pluridisciplinaire HAL, est destinée au dépôt et à la diffusion de documents scientifiques de niveau recherche, publiés ou non, émanant des établissements d'enseignement et de recherche français ou étrangers, des laboratoires publics ou privés. 
1 Noninvasive vascular occlusion with HIFU for venous insufficiency treatment:

2 preclinical feasibility experience in rabbits

3 AUTHORS/INSTITUTIONS:

4

5

6

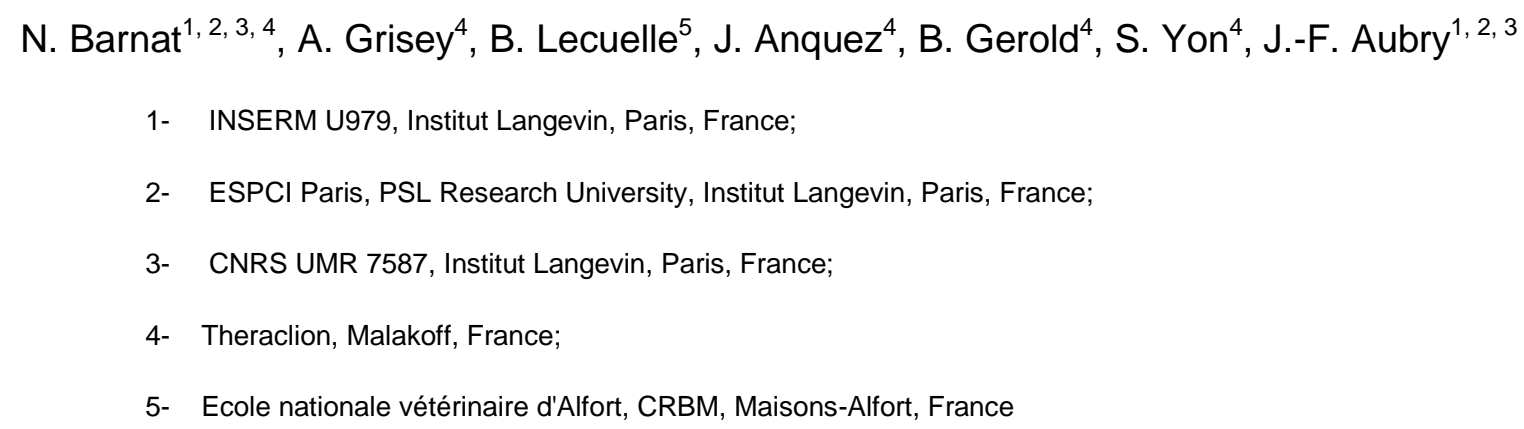

\section{Abstract}

Venous insufficiency is a common disease arising when veins of the lower limb become incompetent. A conventional surgical strategy consists in stripping the incompetent veins. However, this treatment option is invasive and carries complication risks. In the present study, we propose noninvasive high-intensity focused ultrasound (HIFU) to treat lower limbs venous insufficiency, in particular incompetent perforating veins (mean diameter between 2-6 $\mathrm{mm})$.

Sonication parameters were designed by numerical simulations using the k-Wave toolbox to ensure continuous coagulation of a vein with a diameter superior or equal to $2 \mathrm{~mm}$. The selected ultrasound exposures were 4 seconds pulses in continuous wave mode. Two types of sonication were studied: (1) fixed pulses and (2) moving pulses at constant speed (0.75 $\left.\mathrm{mm} \cdot \mathrm{s}^{-1}\right)$ across the vein.

The potential of these exposures to thermally occlude veins were investigated in vivo on rabbit saphenous veins. The impact of vein compression during ultrasonic exposure was also investigated.

Fifteen rabbits were used in these trials. A total of 27 saphenous veins (mean diameter $2.0 \pm$ $0.6 \mathrm{~mm}$ ) were sonicated with a transducer operated at $3 \mathrm{MHz}$. After a mean 15 days follow- 
up, rabbits were euthanized and venous samples were extracted and sent for histologic assessment. Only samples with the vein within the HIFU lesion were considered for analysis. Simulated thermal damage distribution demonstrated that fixed pulses and moving pulses respectively placed every 1.5 and $0.5 \mathrm{~mm}$ along the vein and delivered at an acoustic power of $85 \mathrm{~W}$ and for 4 seconds were able to induce continuous thermal damages along the vein segments.

Experimentally, both treatment parameters (1) and (2) have proven effective to occlude veins with a success rate of $82 \%$. Occlusion was always observed when compression was applied. Our results demonstrate that HIFU can durably and non-invasively occlude veins of diameters comparable to human veins.

Keywords: HIFU; ultrasound; thermal occlusion; vascular occlusion; vein

\section{Introduction}

Venous insufficiency is a common medical condition arising when a high pressure is transmitted from deep to superficial venous system of the lower limbs. High-pressure transmission frequently occurs through retrograde flow. This elevated venous pressure causes the vein to become tortuous and dilated over time. Besides the unsightly appearance of varicosities, venous disease is associated with pain and clinical signs may vary from asymptomatic telangiectasia to achy ulcer [1]. The strategy to treat venous disease consists in ceasing reflux by eliminating the involved incompetent vein segment.

Conventional surgical techniques consist in removing the vein. The invasive nature of surgery leads to the development of minimally invasive procedures such as radiofrequency ablation [2] or endovenous laser ablation [3]. In both cases, after introducing a catheter into the vein, thermal energy is delivered, in order to denature collagen and induce a shrinkage of the vein $[4,5]$.

Although these techniques proved their efficacy, they are not appropriate to treat all leg veins. In case of incompetent perforating veins, thermal ablation is appropriate only for large (>3.5 mm) perforators and may treat perforators only superficially [6]. Furthermore, treating 
pathologic veins can be technically challenging and requires experienced physicians especially for the insertion of the catheter in a deep or tortuous vein.

In this context, high-intensity focused ultrasound treatments (HIFU) could provide a noninvasive alternative to occlude incompetent veins.

Previous studies have demonstrated HIFU occlusion in blood vessels of small diameters only (range $0.5-1.5 \mathrm{~mm}$ ) $[7,8,17-21,9-16]$. The occlusion of large vessels ( $\geq 2 \mathrm{~mm}$ ) has not been reported to the best of our knowledge. We demonstrate here on a rabbit model that HIFU can occlude large veins $(\geq 2 \mathrm{~mm})$, paving the way for a clinical treatment of venous insufficiency with focused ultrasound.

For this purpose, sonication strategies including placement and trajectory of pulses were first identified by numerical simulations and then evaluated on an in vivo model of rabbit veins (range: 1.1-3.7 mm).

\section{Methods}

\section{Ultrasound equipment}

Experiments were performed with the Echopulse ${ }^{\circledR}$ HIFU device (Theraclion, Malakoff, France) used clinically for human breast fibroadenomas [22] and benign thyroid nodules [23] treatments (Figure 1(a)). The system encompasses a treatment head mounted on an articulated arm which includes a single element piezocomposite therapy transducer and a linear confocal imaging probe for real-time monitoring of the treatment (Figure 1(b)). The therapy transducer, operated at $3 \mathrm{MHz}$, has a spherical cap shape with a curvature radius of $38 \mathrm{~mm}$ and an outer diameter of $56 \mathrm{~mm}$. The RF signal applied to the transducer comes from a frequency generator (JJ\&A Instruments, Model RFG-200T1) with an electric power ranging from 10 to $215 \mathrm{~W}$. The ultrasound imaging probe working at a frequency of $6.2 \mathrm{MHz}$ (Vermon, Tours, France) was connected to an Aixplorer® ultrasound system (SuperSonic Imagine, Aix-en-Provence, France) to guide treatments with B-mode images. By construction, the therapeutic focus is located within the imaging plane. A fluid-filled balloon 
(EPack, Theraclion®, Malakoff, France) was fixed to the transducer to ensure acoustic coupling between the transducer and the target. The coupling liquid was circulated and cooled during all the procedure to avoid transducer overheating and skin burns. Cooling is ensured by built-in Peltier modules (Figure 1 (a)). A dedicated software implemented in MATLAB (MathWorks, Inc., Natick, Massachusetts, United States) was used to drive sonications.

(a)

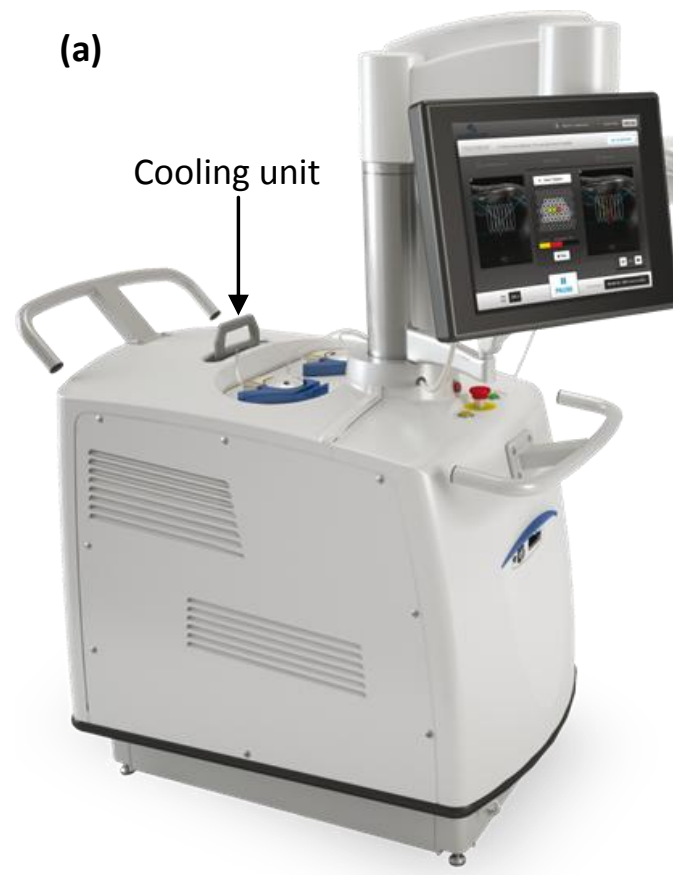

(b)

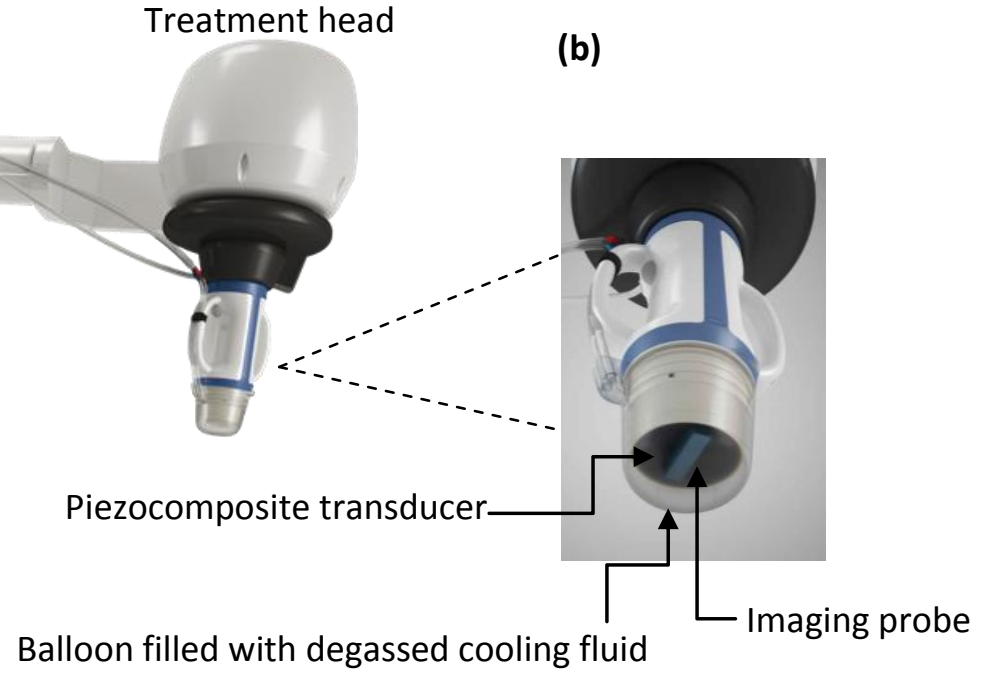

Figure 1: Ultrasound equipment: (a) Echopulse, (b) HIFU transducer.

\section{Treatments simulation}

Simulations were performed to adjust ultrasound exposures layout to adequately sonicate a vein of $2 \mathrm{~cm}$ in length and $2 \mathrm{~mm}$ in diameter. Two types of pulses were studied: (1) fixed pulses and (2) moving pulses at constant speed $\left(0.75 \mathrm{~mm} \cdot \mathrm{s}^{-1}\right)$ along a line orthogonal to the longitudinal axis of the vein. In both cases, we used 4-second sonications delivered in continuous wave mode at an acoustic power of $85 \mathrm{~W}$ (typical power used in clinics and in our experiments) and with the focus located at $15 \mathrm{~mm}$ under the skin. Acoustic pressure field, temperature rise and, ultimately, thermal damages extent were simulated. 
Geometrical model

The modelled HIFU transducer has the same geometry than the therapy transducer described in the Ultrasound equipment section. The frame of reference of the transducer was defined as follows: the origin corresponds to the HIFU transducer focus. $\mathrm{X}$ is the axis of the imaging transducer and oriented along the left-to-right direction of the generated images. Z denotes the main ultrasound propagation axis, pointing towards the subject anatomy. $Y$ results from the cross product of $\mathrm{Z}$ and $\mathrm{X}$, for the frame $(X, Y, Z)$ to be orthonormal and righthanded.

In the simulations, the vein was considered as collapsed and the blood flow abolished. Thus, the vein itself was not modelled. We assumed that the ultrasound beam propagates through 3 layers, from top to bottom: (1) the cooling liquid contained in the balloon fixed to the transducer; (2) the skin and (3) the muscle. Skin was modelled as a 2-mm thick layer. For illustration purposes, a 2D view of the geometrical model is shown in Figure 2.

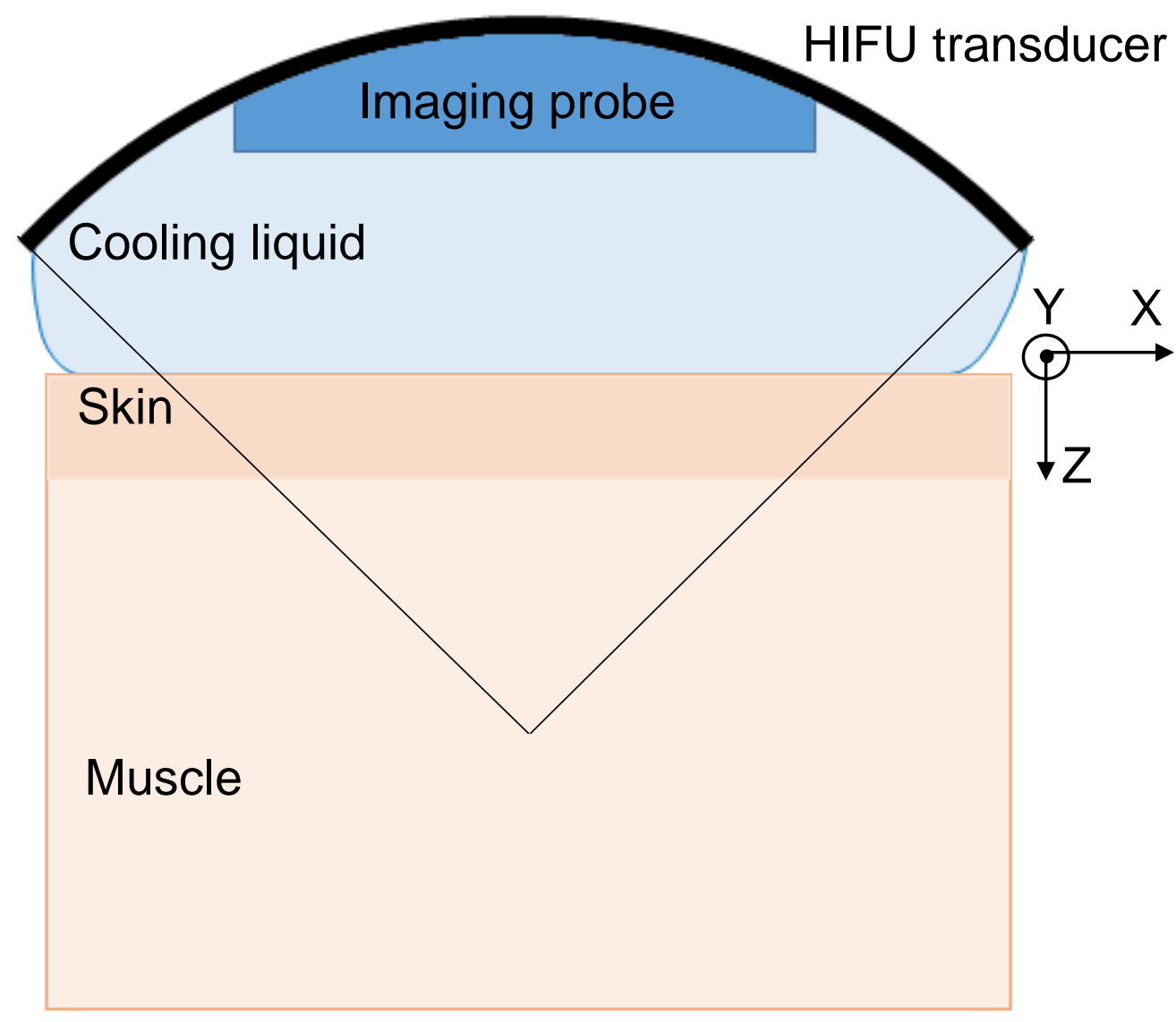


113

114

115

116

117

118

119

120

121

122

123

124

125

126

127

128

129

130

131

132

133

134

135

Acoustic simulation

Acoustic simulations were performed using the k-Wave toolbox 1.2 [24]. The toolbox solves the system of coupled first-order partial differential equations comprising momentum conservation, mass conservation and pressure-density relation.

To solve the system of coupled acoustic equations, k-Wave uses a k-space pseudospectral method where spatial gradients are computed using the Fourier collocation spectral method [24]. Although the mathematical approach used in k-Wave is efficient, the 3D simulation of the HIFU beam is costly in terms of memory. In our case, at $3 \mathrm{MHz}$ and considering a domain of $60 \times 60 \times 46 \mathrm{~mm}$, the simulation of the nonlinear propagation up to the fifth harmonic with the minimum of two points per wavelength requires a grid of $1.37 \times 10^{9}$ points. Hence, to reduce memory requirements, we used a "layer by layer" approach [25]. The computational grid is divided into finer and finer layers along the main propagation axis and we simulated ultrasound propagation from the transducer to $3 \mathrm{~mm}$ beyond the focus. We respectively used one layer for the cooling liquid, one layer for the skin and five layers for muscle tissue. Nonlinearities were modeled up to the fifth harmonic in the widest layer.

The size of the smallest layer was $4 \times 4 \times 4 \mathrm{~mm}$ (corresponding to $8 \times 8 \times 8$ wavelengths), with a spatial grid step of $49.8 \mu \mathrm{m}$. A perfectly matched layer was used to avoid reflections at the boundaries of the domain.

The Courant-Friedrichs-Lewy (CFL) number was set to 0.5 resulting in a smallest time step of $14.8 \mathrm{~ns}$. The pressure acoustic source term was computed as:

$$
p^{2}=\frac{2 P_{a c} \rho c_{s}}{S_{\text {transducer }}}
$$

The cooling liquid, skin, fat and muscle tissue were modeled as homogenous media with the acoustic properties listed in 
Tissue properties were assumed to remain constant for the full procedure period. Variability of parameters with temperature was neglected for all simulations.

\begin{tabular}{|l|c|c|c|}
\hline & Cooling liquid [26] & $\begin{array}{c}\text { Superficial tissue } \\
\text { (skin...)[26] }\end{array}$ & Muscle [27] \\
\hline Sound speed $\left({\left.\mathrm{m} . \mathrm{s}^{-1}\right)}^{-1}\right.$ & 1495 & 1547 & 1587 \\
\hline Density $\left(\mathrm{kg} \cdot \mathrm{m}^{-3}\right)$ & 1000 & 1214 & 1041 \\
\hline Attenuation at 3 $\mathrm{MHz}\left[\mathrm{dB} \cdot \mathrm{cm}^{-1}\right]$ & 0 & 2.2 & 3.0 \\
\hline Acoustic non-linearity parameter & 4.9 & 9.0 & 7.8 \\
\hline
\end{tabular}

Table 1: Acoustic properties of tissues used for simulations.

Thermal simulation

Tissue heating was modeled using the Pennes's bioheat equation [28]. The equation was solved in 3D using a first-order explicit Euler scheme in time and a centered scheme in space.

The time step was $50 \mathrm{~ms}$ and the spatial step was $200 \mu \mathrm{m}$. The grid size was $38 \times 38 \times 29$ $\mathrm{mm}$.

The heat source term was computed as stated in [25]. The classic attenuation model

147 (absorption + scattering) was considered, and thermal rise was generated by the absorbing component.

The tissue initial temperature was set to $T_{0}=39.5^{\circ} \mathrm{C}$ which is the mean body temperature for a rabbit [29] and Dirichlet boundary conditions were used with $T_{\text {boundaries }}=T_{0}$. We modelled skin cooling as a heat flux at skin surface considering that the temperature of the cooling fluid was $10^{\circ} \mathrm{C}$ (value achieved during experiments) and the heat transfer coefficient between skin and liquid was set to $320 \mathrm{~W} \cdot \mathrm{m}^{2} \cdot \mathrm{K}^{-1}$ based on previous experiments. To determine this value, temperature of skin was first measured several times with a thermocouple slipped between skin and the balloon in which circulated cooled liquid. Thereafter by assuming that heat flow at skin is proportional to the difference of temperatures between skin and a characteristic temperature of the cooling liquid, the value of $320 \mathrm{~W} \cdot \mathrm{m}^{2} \cdot \mathrm{K}^{-1}$ has been assigned. As experimentally, the cooling time between subsequent sonications was set to 15 seconds. 
159 The tissue properties used in thermal simulations are listed in Table 2 and were assumed 160 invariant with temperature in simulations.

\begin{tabular}{|l|c|}
\hline & Muscle[30] \\
\hline $\begin{array}{l}\text { Specific heat capacity }\left(\mathrm{J} \cdot \mathrm{kg}^{-1} \cdot \mathrm{K}\right. \\
1)\end{array}$ & 3600 \\
\hline Thermal conductivity $\left(\mathrm{W} \cdot \mathrm{m}^{-1} \cdot \mathrm{K}^{-1}\right)$ & 0.47 \\
\hline Perfusion $\left(\mathrm{s}^{-1}\right)$ & 0.018 \\
\hline
\end{tabular}

Table 2: thermal properties of media used in thermal simulation.

162

163

164

165

166

167

168

169

170

171

172

173

174

175

176

177

\section{Thermal damage}

To achieve vessel sealing, sufficient thermal damage shall be induced to the vessel wall.

Modelling of vascular thermal damage [31] suggests that vessel thermal damage correlates with the denaturation of collagen fibrils, which begins at $62^{\circ} \mathrm{C}[32]$.

In this study, extent of thermal damage to vessels was evaluated based on a dedicated thermal damage model.

To assess the level of damage induced to vessels, we implemented the model described by Agah [31]. By considering denaturation of collagen as a first-order reaction, damage was modelled using a general Arrhenius equation:

$$
\Omega(t)=\ln \left(\frac{c(0)}{c(\tau)}\right)=A_{f} \int_{0}^{\tau} \exp \left(\frac{-E_{a}}{R T(t)}\right) d t
$$

Where:

$\Omega(\mathrm{t})$ is the damage parameter. $c(0), c(\tau)$ are the concentrations of the undamaged molecules at the beginning and at time $\tau$ respectively. $A_{f}$ is a coefficient of rate process (frequency factor), $E_{a}$ the activation energy, $R$ the universal gas constant, and $T$ the temperature. $A_{f}$ and $E_{a}$ were set to $A_{f}=5.6 \times 10^{63} \mathrm{~s}^{-1}$ and $E_{a}=430 \mathrm{~kJ} \mathrm{~mol}^{-1}$ according to [31].

Degree of vessel damage is appraised by $\Omega(t)$, where $\Omega(t)=1$ defines the first noticeable irreversible damage and formally corresponds to the denaturation of $63 \%$ of the native proteins [31]. As we are looking for an extensive damage to the vein, we set the threshold for thermal damage to $\Omega(t)=5$, which formally corresponds to the denaturation of $99 \%$ of the collagen. 


\section{Animals}

All animal work was approved by the institutional ethics committee for animal experiments (agreement number CE16/2016082512126208). Experiments were carried out according to the guidelines of the French National Comity for animal trials C.N.R.E.E.A (Comité national de réflexion éthique sur l'expérimentation animale). New-Zealand white rabbits $(n=15), 5$ males and 10 females, 2 to 4 months $(3 \pm 1)$ old and weighing 2.7 to $4.5 \mathrm{~kg}(3.5 \pm 0.5)$, were used for the experiments. HIFU exposures were applied on medial saphenous veins. Prior to sonications, the animals were anesthetized intramuscularly with a mixture of Ketamine $(0.33$ $\mathrm{mg} / \mathrm{kg})$, Domitor $(0.5 \mathrm{mg} / \mathrm{kg})$ and Valium $(0.17 \mathrm{mg} / \mathrm{kg})$. They were then intubated with an endotracheal tube and ventilated with isoflurane to be kept under anesthesia throughout the procedure. The fur of their hind limbs was shaved with a hair trimmer and then carefully depilated with a depilatory cream to ensure good acoustic coupling and prevent skin burns.

\section{HIFU procedure}

Before the procedure, the rabbit was placed on the table in supine position to access the targeted vein. Ultrasonic gel (Polysonic Parker Laboratories, Inc., Fairfield, NJ) was applied to the area to be treated to ensure appropriate coupling. B-mode ultrasound and color Doppler imaging were used to position the focus on the vein.

27 medial saphenous veins (average diameter of $2 \mathrm{~mm}$ ) were exposed to HIFU.

Blood flow is known to hamper thermal therapies by cooling down the vein wall [33-37]. Therefore, several configurations based on previous simulations were tested during the HIFU treatments: (1) 5 veins were treated with multiple pulses (median $1.5 \mathrm{~mm}$ spacing) distributed along the target vein (Figure 3A)); (2) 14 veins underwent the same treatment protocol than the one used in configuration (1) but the hind limb was elevated to about 25 degrees from the horizontal to diminish blood flow (Figure 3 B)); and (3) 8 veins were sonicated with moving pulses $\left(0.75 \mathrm{~mm} . \mathrm{s}^{-1}\right.$ along a $3-\mathrm{mm}$ line transecting the vein) (Erreur! Source du renvoi introuvable.) and were mechanically compressed by pressing a finger on the groin during exposures to stop blood flow and minimize its heat sink effect. Rear limbs elevation empty 
veins of their intraluminal blood and induce venous spasm (illustrated in Erreur ! Source du

renvoi introuvable. for configurations (2) and (3)). The average diameter of the vein after proximal compression was of $1 \mathrm{~mm}$. According to simulations, for configuration 3 , the spacing between moving pulses was reduced to $0.5 \mathrm{~mm}$ to account for the smaller lesion size in the longitudinal direction (Figure 3C)

Thus, the number of sonications was increased to sonicate the same length of $2 \mathrm{~cm}$.

A)

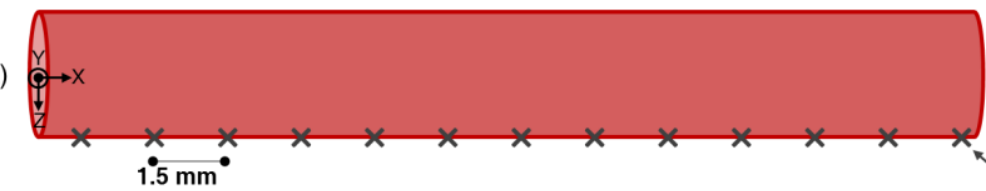

B)

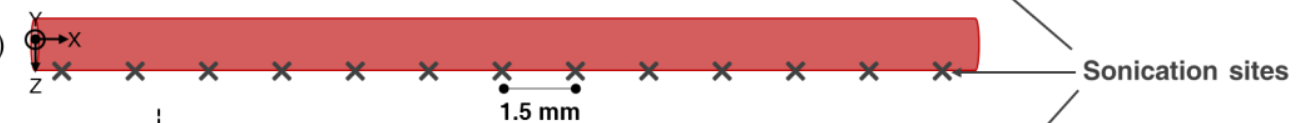

C)

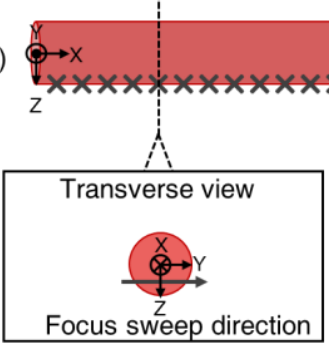

Figure 3: Schema illustrating dispositions of HIFU exposures. A), B) and C) stand for configurations (1), (2) and (3) respectively.

For all cases, HIFU sonications were applied for 4 seconds and at an acoustic power of $83 \pm$ $10 \mathrm{~W}$ (obtained by multiplying electric power by the $70 \%$ efficiency of the transducer). The corresponding spatial-peak intensity (linear extrapolation from low power hydrophone measurement in water is $28 \mathrm{~kW} . \mathrm{cm}^{-2}$. A minimum time period of $15 \mathrm{~s}$ was set between two sonications to allow the skin to cool down. Experimental protocols are summarized in Table 3.

\begin{tabular}{|c|c|c|c|}
\hline Experimental protocol ID & 1 & 2 & 3 \\
\hline Number of HIFU exposed veins & 5 & 14 & 8 \\
\hline \multirow{2}{*}{ Sonication types } & Fixed pulses $1.5 \mathrm{~mm}$ & Fixed pulses $1.5 \mathrm{~mm}$ & Linear track with sites $0.5 \mathrm{~mm}$ apart \\
& apart & apart & Hind limb elevated \\
\hline
\end{tabular}




\begin{tabular}{|l|l|l|l|}
\hline & & Hind limb elevated & Vein compressed \\
\hline
\end{tabular}

Table 3: Experimental conditions

225 Histological protocol

226 After the experiments, the rabbits were recovered from anesthesia and were monitored for at

227 least 15 days after treatment, to assess the sustainability of the effects of HIFU exposures on veins. Animals were then euthanized by intravenous injection of Pentobarbital ( $1 \mathrm{~mL} / \mathrm{kg})$. The day of euthanasia, the animals underwent a post mortem dissection and the targeted vessel was harvested. In some cases, the perivenous conjunctive tissue was adherent and the vein could not be separated. In such cases, the vein was sent for analysis with the attached perivenous tissue.

233 The proximal tip of each venous section was sutured, preserved in identified cassettes, fixed in $4 \%$ formalin and sent for histologic examination. Samples were then cross-sectioned into 3 subsections and included in paraffin. 4- $\mu \mathrm{m}$ slices were cut and stained with haematoxylineosin (HE) for evaluation. Each section was evaluated without knowledge of the detailed treatment status.

238 Excision of the proper vein segment is difficult since other veins branch in the vicinity of the 239 target. Therefore, samples were taken into account only when a vein was present on the 240 slide and was located within the HIFU lesion.

241 A venous sample from untreated region was also extracted and served as a control.

242 Changes were graded as: normal vein (0), reactive endothelium (1), myoendothelial proliferation (2), acute fibrinous thrombi (3) and thrombus organization (4). 


\section{Results}

245 Numerical model

246 Ultrasound pressure field

247 Figure 4 shows the rms acoustic pressure field profile in the YZ plane simulated with the

248 "layer by layer" approach. Simulations were ran at $3 \mathrm{MHz}$ and at an acoustic power of $85 \mathrm{~W}$.

249

250

251

252

253

254

255

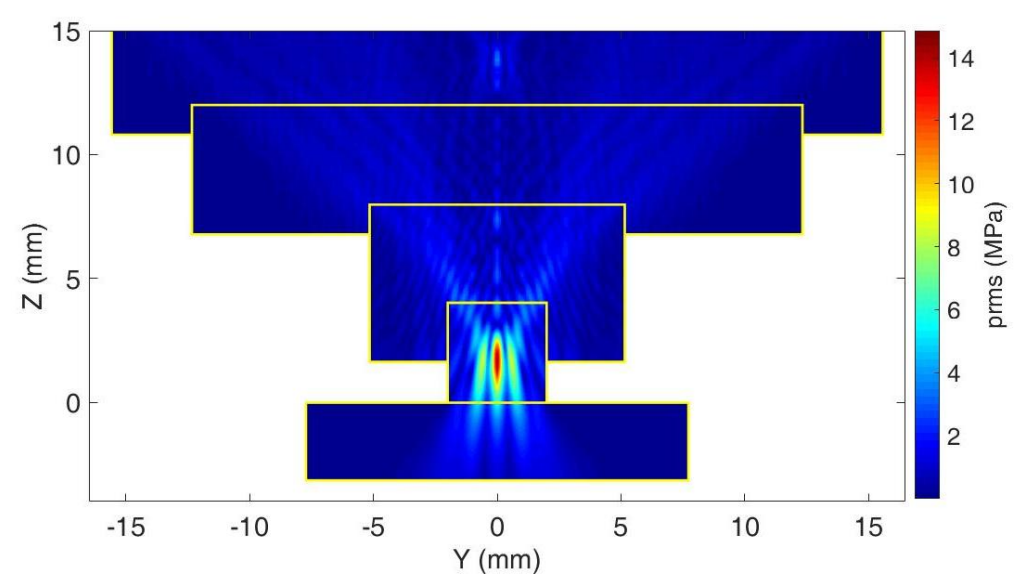

Figure 4: Simulated rms pressure field of the geometrical model in the YZ plane simulated.

Pressure is expressed in MPa. Yellow rectangles represent the limits of the subsequent layers.

\section{Thermal damages}

Temperature elevation at the expected location of the upper vein wall $(2 \mathrm{~mm}$ above the focal point centered on the lower vein wall) is plotted on Figure 5 for configurations (2) and (3). 


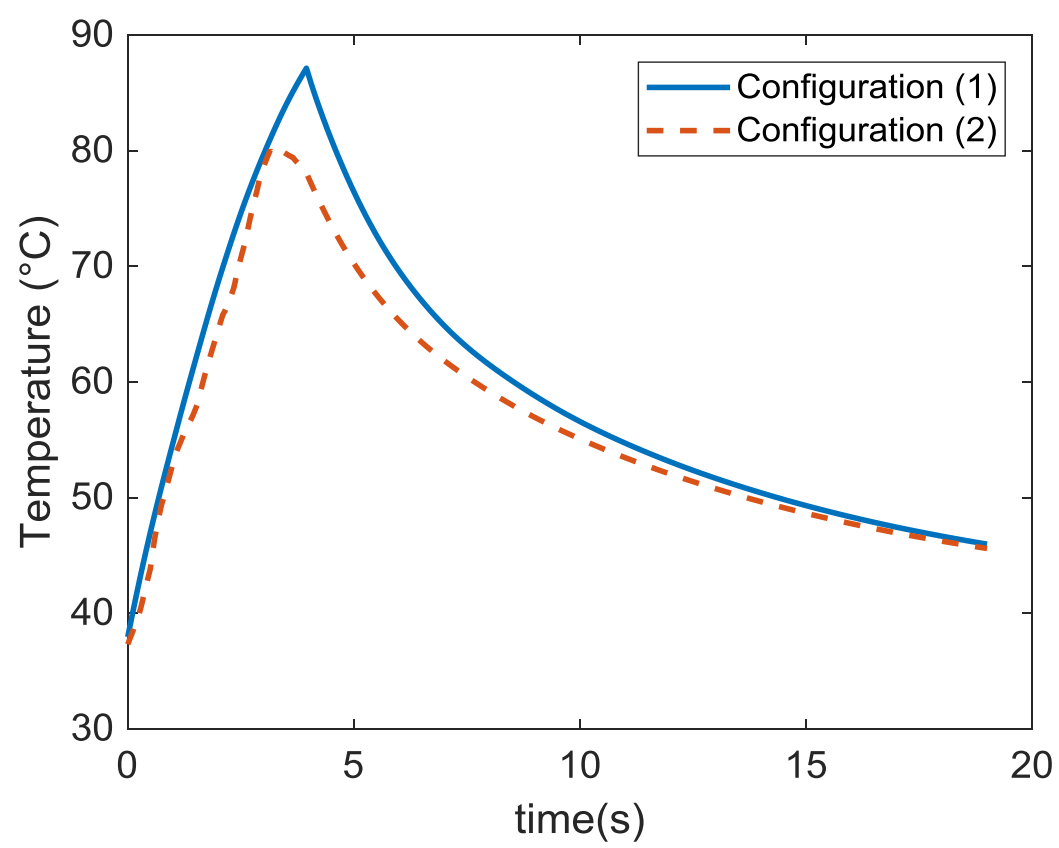

Figure 5: Simulated temperature elevation at the location of the vein wall during $4 \mathrm{~s}$ sonification followed by $15 \mathrm{~s}$ cooling for unitary fixed pulse (solid line) and moving pulse (dash line).

For unitary fixed and moving pulse, the extent of the coagulated zone as defined using the thermal damage model was $1.2 \mathrm{~mm}$ and $0.6 \mathrm{~mm}$ along the vein respectively and $1.8 \mathrm{~mm}$ and $2.7 \mathrm{~mm}$ in the orthogonal direction to the vein respectively.

263 To induce homogeneous and extensive heating of a vein $2 \mathrm{~cm}$ in length and $2 \mathrm{~mm}$ in diameter, we considered: (1) for fixed pulses, 13 sonications with a spacing of $1.5 \mathrm{~mm}$ and (2) for moving pulses, 37 sonications moving along the cross sectional axis with a spacing of $0.5 \mathrm{~mm}$ along the longitudinal axis of the vein.

Figure 6 and Figure 7 show the results of thermal damage distribution for such treatments:

268 (1) 13 fixed pulses and (2) 37 moving pulses respectively. An iso-contour representing the 269 area corresponding to denaturation of $99 \%$ of native proteins is displayed.

270 Distribution of thermal damage simulations are displayed using maximum intensity 271 projections. 
272

273 Figure 6: Maximum intensity projected damage map at the end of a treatment comprising 274 thirteen 4-s fixed pulses delivered $1.5 \mathrm{~mm}$ apart at an acoustic power of $85 \mathrm{~W}$ and with the 275 focus located at $15 \mathrm{~mm}$ under skin. Iso-contour corresponding to: the thermal damage where $27699 \%$ of native proteins denature is displayed in black.

278 Figure 7: Projected damage map at the end of a treatment comprising 37 4-s pulses during 279 which the focus was moved at $0.75 \mathrm{~mm} \cdot \mathrm{s}^{-1}$. Sonications were delivered at an acoustic power of $85 \mathrm{~W}$, with a spacing of $0.5 \mathrm{~mm}$ and with the focus located at $15 \mathrm{~mm}$ under skin. Iso281 contour corresponding thermal damage where $99 \%$ of native proteins denature is displayed 282 in black. 
To quantify the impact of the trajectory, attention has been given to the extent of the region corresponding to protein denaturation.

Damaged zones in the XY plane of the vein for treatment layouts (1) and (2) are reported in Table 4.

\begin{tabular}{|c|c|c|}
\hline Treatments ID & Damaged zone & Lesion area \\
\hline$(1)$ & $19.2 \times 2.4 \mathrm{~mm}^{2}$ & $42.8 \mathrm{~mm}^{2}$ \\
\hline$(2)$ & $19.2 \times 4.2 \mathrm{~mm}^{2}$ & $72.0 \mathrm{~mm}^{2}$ \\
\hline
\end{tabular}

Table 4: Simulated results in terms of damaged areas for treatment plannings (1) and (2)

After HIFU exposures, vessel damage can be observed through vessel shrinkage as illustrated in the following ultrasound image (Figure 8).

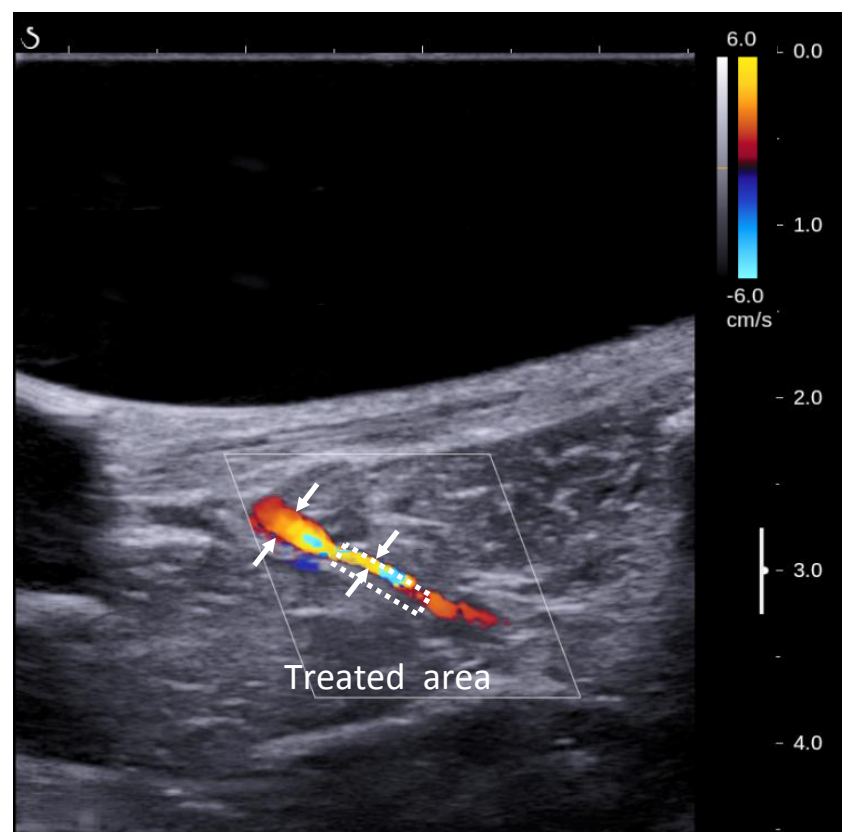

Figure 8: Acute vascular shrinkage following HIFU pulses

Histological findings

Clinical follow-up of the animals showed that recovery after HIFU treatments were well tolerated. All animals survived until the day of euthanasia and no abnormal behavior was noted postoperatively. All animals continued their normal pattern of feeding.

296 As mentioned in Histological protocol, only samples satisfying acceptance criterion were considered in the study. 
In total and excluding the control sample, 17 samples (63\%) were taken into account in this 299 study. Histological results are reported in Table 5.

\begin{tabular}{|c|c|c|c|}
\hline Experimental protocol ID & 1 & 2 & 3 \\
\hline Number of accepted samples & 1 & 10 & 6 \\
\hline \multirow{2}{*}{ Sonication types } & Fixed pulses $1.5 \mathrm{~mm}$ & Fixed pulses $1.5 \mathrm{~mm}$ & Linear track with sites $0.5 \mathrm{~mm}$ apart \\
& apart & Hind limb elevated & Heind limb elevated \\
& & & $\mathbf{3}$ compressed \\
\hline Follow-up duration & 15 days & 15 days & $\mathbf{3 : 3 / 6}$ \\
\hline Occlusion score & $\mathbf{0 : 1 / 1}$ & $\mathbf{0 : 2 / 1 0}$ & $\mathbf{3 : 3}$ : \\
\hline
\end{tabular}

301 The follow-up duration indicated in Table 5 corresponds to the median value. It is however necessary to emphasize that follow-up duration extended from 7 days for the shortest one to 19 days for the longest one due to the availability of the animal facility.

304 For all samples treated with fixed pulses and with a score superior or equal to 3, histological 305 findings revealed a thrombo-vasculitis of the saphenous vein characterized by a transmural 306 thickening and collapse of the lumen. Fibrinous thrombi were also present. These lesions are 307 irreversible in nature or expected to be irreversible (as assessed by the histopathologist) for 308 the samples with a follow-up duration inferior to 13 days. Lesions were expected to evolve 309 towards the formation of large fibrotic scars incorporating saphenous veins. Figure 9 shows 310 illustrative HE stained histologic cross sections. 

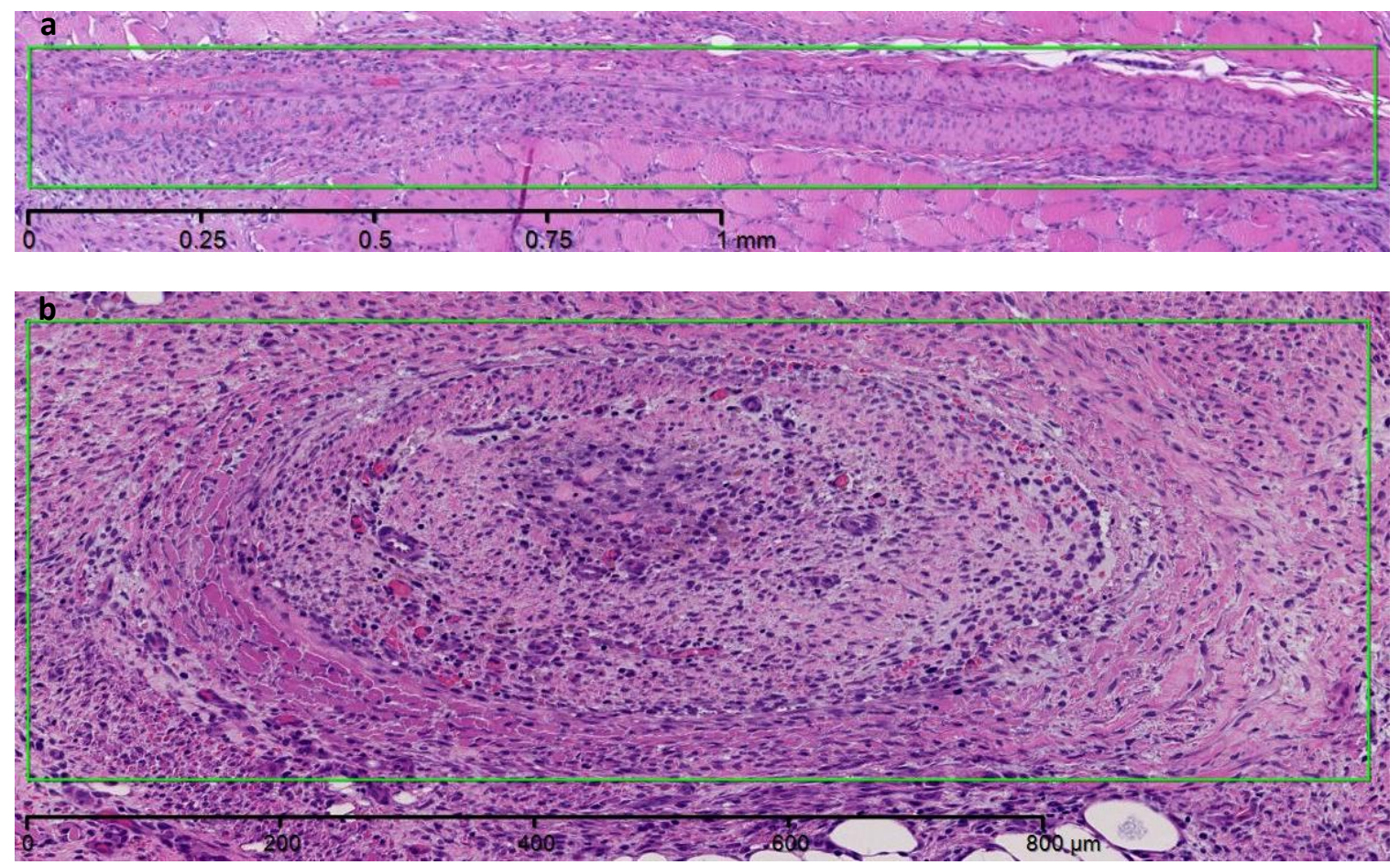

Figure 9: HE sections (magnification $5 \times$ ) of representative saphenous veins (green rectangles) showing a transmural thickening and collapse of their lumens. The sections (a)

The lesions observed on samples sonicated with moving pulses were histologically identical to those treated with fixed pulses. However, variability in the severity of the lesions was observed between samples. The majority (73\%) of samples treated with fixed pulses showed

a severe thrombo-vasculitis while lesions were evenly distributed between severe and moderate for samples sonicated with moving pulses.

\section{Discussion}

321 The feasibility of inducing sustainable vascular occlusion with HIFU thermal effects was 322 demonstrated since histology reported $82 \%$ of vascular occlusion. Occlusion was successful 323 in all cases where compression was applied.

324 Histological analysis systematically showed severe lesions for samples which underwent 325 fixed point-by-point sonications and moderate lesions for half of the ones that were treated 
by moving pulses. With moving pulses, the energy delivered is more spread and results in less severe lesions.

However, vein samples that showed no occlusion were treated with fixed pulses. According to simulations in the orthogonal direction to the vein diameter, coagulated zone after fixed pulses is barely enough to cover the vein. Fixed pulses are effective when the vein wall is completely encompassed in the lesion.

After fixed pulses, the coagulated zone is $2.4 \mathrm{~mm}$ in diameter and does not cover the whole circumference of all targeted veins (diameter range between $[1.1-3.7 \mathrm{~mm}]$.

Conversely, moving pulses cover an area 1.8 times wider which reliably damage the whole circumference of all the veins. However, treatment with moving pulses required nearly three times more sonications than treatment with fixed pulses to treat a same vein segment.

The lack of symmetry observed in the figure 5 resulted from heat accumulation effect. As sonications are delivered, thermal energy deposited by previous pulse is added to energy deposition of current pulse. There is therefore an overlap in heat accumulation between successive pulses.

Although temperature dependence of ultrasound parameters has been demonstrated experimentally $[38,39,48,49,40-47]$, constant acoustic parameters were used in the simulation as done by other teams[50-53]

In this study, we did not investigate focus movement speeds higher than $0.75 \mathrm{~mm} . \mathrm{s}^{-1} \mathrm{but}$ further work may be performed to assess the highest focus speed that can lead to both a fast and an effective occlusion.

Considering the good correlation between simulations and histologic findings, the model used to assess thermal damage in the vein, based on the denaturation of collagen, appears to be consistent. This is supported by the study conducted by Fujiwara et al [54] where vessel occlusion was observed when peak temperature of the insonated sample hit $98^{\circ} \mathrm{C}$ but not at $47^{\circ} \mathrm{C}$ or $54^{\circ} \mathrm{C}$. 
Area corresponding to denaturation of $99 \%$ of native proteins correlates with the region where temperature reached $85^{\circ} \mathrm{C}$. This temperature is also the level recommended by radiofrequency closure ablation to seal veins.

By heating homogeneously the intima to $85^{\circ} \mathrm{C}$, we would mostly likely achieve total coagulation of the vein wall.

In our study, the three occlusion-free samples correspond to treatments without compression. We hypothesize that blood flow could have acted as a heat sink which prevented the temperature elevation of the vein wall from reaching sufficient levels. Compression should be considered for future clinical treatments as it helps to abolish blood flow and to decrease lumen area.

The high temperature elevations obtained in the simulations indicate that in our study, thermal effects of HIFU are expected to play a major role in our venous occlusions. Thermal mechanism compares favorably to the use of purely mechanical occlusion effects as reported by Hwang et al [55], which lead to a recanalization of the veins after the treatment. Hwang et al [55] used pulsed HIFU exposures with a low duty cycle in synergy with ultrasound contrast agent. The treatment was effective but could not maintain rabbit auricular vein occlusion over 14 days. With similar pulsing regime (9 MPa peak rarefaction pressure, 1-Hz pulse repetition frequency), Zhou et al [15] demonstrated a sustainable occlusion with mechanical effects of HIFU but only by injecting pro-inflammatory agents corresponding to the detergents found in sclerosing agents [56].

Groups who used ultrasound alone reported a temporary occlusion that did not exceed one week after treatments $[8,54,57]$. Notwithstanding that they have demonstrated occlusion in small veins $(<1.5 \mathrm{~mm})$, no long-term occlusion was proved.

Our exposure ultrasound parameters without additives were sufficient to induce venous closure. To date and to the best of our knowledge, no other study reported noninvasive permanent occlusion on veins of similar size, with the use of thermal effects of HIFU. 


\section{Conclusion}

379 In this study, two sonication strategies have been identified and evaluated in a rabbit model. In vivo experiments have demonstrated that thermal ablation with HIFU can induce permanent sealing of veins of up to $3.7 \mathrm{~mm}[1.1-3.7 \mathrm{~mm}]$ in diameter. HIFU is thereby a promising alternative to treat incompetent perforating veins. The treatment parameters used in this study provide insights for subsequent clinical trials. Vein compression was identified as a key factor contributing to successful vascular occlusion since it avoided the cooling effect of the blood flow.

Future work should demonstrate the ability to coagulate larger veins (in a larger animal model) similar to the great saphenous vein and its tributaries.

\section{References}

389 [1] Alam M, Nguyen T H and Dover J S 2006 Treatment of Leg Veins (Elsevier)

390 [2] Goldman MP 2000 Closure of the great saphenous vein with endoluminal radiofrequency thermal heating in combination with ambulatory phlebectomy:

[3] Navarro L, Min R J and Bone C 2001 Endovenous laser: a new minimally invasive method of treatment for varicose veins-preliminary observations using an $810 \mathrm{~nm}$ diode laser Dermatol Surg 27 117-22

[5] Bergan J, Kumins N, Owens E and Sparks S 2002 Surgical end endovascular

[4] Manfrini S, Gasbarro V, Danielsson G, Norgren L, Chandler J G, Lennox A F, Zarka Z treatment of lower extremity venous insufficieency J. Vasc. Interv. Radiol. 13 563-8 a. and Nicolaides A N 2000 Endovenous management of saphenous vein reflux J. Vasc. Surg. 32 330-42

Dillavou E D, Harlander-Locke M, Labropoulos N, Elias S and Ozsvath K J 2016 Current state of the treatment of perforating veins J. Vasc. Surg. $4131-5$

7] Delon-Martin C, Vogt C, Chignier E, Guers C, Chapelon J Y and Cathignol D 1995 
Venous thrombosis generation by means of high-intensity focused ultrasound Ultrasound Med. Biol 21 113-9

[8] Hynynen K, Chung A H, Colucci V and Jolesz F A 1996 Potential adverse effects of high-intensity focused ultrasound exposure on blood vessels in vivo Ultrasound Med. Biol 22 193-201

[9] Hynynen K;, V C, Chung A and Jolesz F 1996 Noninvasive arterial occlusion using MRI-guided focused ultrasound Ultrasound Med. Bio/ 22 1071-7

[10] Rivens I H, Rowland I J, Denbow M, Fisk N M, Ter Haar G R and Leach M O 1999 Vascular occlusion using focused ultrasound surgery for use in fetal medicine Eur. J. Ultrasound 9 89-97

[11] Denbow M L, Rivens I H, Rowland I J, Leach M O, Fisk N M and ter Haar G R 2000 Preclinical development of noninvasive vascular occlusion with focused ultrasonic surgery for fetal therapy J Obs. Gyneco 387-92

[12] Ishikawa T, Okai T, Sasaki K, Umemura S ichiro, Fujiwara R, Kushima M, Ichihara M and Ichizuka K 2003 Functional and histological changes in rat femoral arteries by HIFU exposure Ultrasound Med. Biol. 29 1471-7

[13] Fujiwara K, Takeuchi H, Itani K, Yoshinaka K, Sasaki A, Azuma T, Sakuma I, Matsumoto Y, Medical H A, High T, Focused I and Aloka H 2011 Real time HIFU beam imaging Proc. 2001 Symp. Ultrason. Electron. 32 583-4

[14] Hwang J H, Tu J, Brayman A A, Matula T J and Crum L A 2006 Correlation between inertial cavitation dose and endothelial cell damage in vivo Ultrasound Med. Biol 32 $1611-9$

[15] Zhou Y, Zia J, Warren C, Starr F L, Brayman A A, Crum L A and Hwang J H 2011 Targeted long-term venous occlusion using pulsed high-intensity focused ultrasound combined with a pro-inflammatory agent Ultrasound Med Bio/ 37 1653-8

[16] Hwang J H, Brayman A A, Reidy M A, Matula T J, Kimmey M B and Crum L A 2005 Vascular effects induced by combined $1-\mathrm{MHz}$ ultrasound and microbubble contrast agent treatments in vivo Ultrasound Med. Bio/31 553-64 
[17] Hwang J H, Zhou Y, Warren C, Brayman A A and Crum L A 2010 Targeted venous occlusion using pulsed high-intensity focused ultrasound. IEEE Trans. Biomed. Eng. 57 37-40

[18] Ichizuka K, Ando S, Ichihara M, Ishikawa T, Uchiyama N, Sasaki K, Umemura S, Matsuoka R, Sekizawa a, Okai T, Akabane T and Kushima M 2007 Application of high-intensity focused ultrasound for umbilical artery occlusion in a rabbit model. Ultrasound Obstet. Gynecol. 30 47-51

[19] Ichiharan Mitsuyoshi, Sasaki K, Umemura S-I, Kushima M and Okai T 2007 Blood flow occlusion via ultrasound image-guided high-intensity focused ultrasound and its effect on tissue perfusion Ultrasound Med. Biol 33 452-9

[20] Shaw C J, ter Haar G R, Rivens I H, Giussani D A and Lees C C 2014 Pathophysiological mechanisms of high-intensity focused ultrasound-mediated vascular occlusion and relevance to non-invasive fetal surgery J. R. Soc. Interface 11

[21] Zhang M, Fabiilli M L, Haworth K J, Fowlkes J B, Kripfgans O D, Roberts W W, Ives K A and Carson P. 2010 In vivo investigation of acoustic droplet vaporization for occlusion in canine kidney Ultrasound 36 1691-703

[22] Kovatcheva R, Guglielmina J-N, Abehsera M, Boulanger L, Laurent N and Poncelet E 2015 Ultrasound-guided high-intensity focused ultrasound treatment of breast fibroadenoma-a multicenter experience $J$. Ther. Ultrasound 31

[23] Esnault O, Franc B, Leenhardt L, Rouxel A, Ménégaux F and Lacoste F 2006 HighIntensity Focused Ultrasound (Hifu) Treatment For Thyroid Nodules: Experimental and First Clinical Studies 6th International Symposium on Therapeutic Ultrasound vol 911 (AIP) pp 98-103

[24] Treeby B E and Cox B T 2010 k-Wave: MATLAB toolbox for the simulation and reconstruction of photoacoustic wave fields J. Biomed. Opt. 15 021314-1: 021314-12

[25] Grisey A, Yon S, Letort V and Lafitte P 2016 Simulation of high-intensity focused ultrasound lesions in presence of boiling J. Ther. Ultrasound 411

[26] Grisey A, Heidmann M, Letort V, Lafitte P and Yon S 2016 Influence of Skin and 
Subcutaneous Tissue on High-Intensity Focused Ultrasound Beam: Experimental Quantification and Numerical Modeling Ultrasound Med. Biol 42 2457-65

462

463

464

465

466

467

468

469

470

471

472

473

474

475

476

477

478

479

480

481

482

483

484

[27] Duck F A 1990 Acoustic Properties of Tissue at Ultrasonic Frequencies Phys. Prop. Tissues 73-135

[28] Pennes H H 1948 Analysis of tissue and arterial blood temperatures in the resting human forearm. J. Appl. Physiol. 1 93-122

[29] Kozma C, Macklin W, Cummins L M and Mauer R 1974 The Biology of the Laboratory Rabbit ed S H Weisbroth, R E Flatt and A L Kraus (United States of America: Academic Press Inc. (London) Ltd.)

[30] Duck F A 1990 Thermal Properties of Tissue Phys. Prop. Tissues 9-42

[31] Agah R, Pearce J A, Welch A J and Motamedi M 1994 Rate process model for arterial tissue thermal damage: Implications on vessel photocoagulation Lasers Surg. Med. 15 $176-84$

[32] Pankhurst K 1947 Incipient Shrinkage of Collagen and Gelatin Nature 159538

[33] Chent L, Ter Haart G, Hill C R, Dworkint M, Carnochant P, Young H and Benstedt J P M 1993 Physics in Medicine \&amp; Biology Effect of blood perfusion on the ablation of liver parenchyma with high-intensity focused ultrasound Phys. Med. Biol 38 1661-73

[34] Goldberg S N, Stein M C, Gazelle G S, Sheiman R G, Kruskal J B and Clouse M E 1999 Percutaneous Radiofrequency Tissue Ablation: Optimization of PulsedRadiofrequency Technique to Increase Coagulation Necrosis J. Vasc. Interv. Radiol. $907-16$

[35] Heisterkamp J, Hillegersberg R van, Mulder P G ., Sinofsky E L and ljzermans J N . 1997 Importance of eliminating portal flow to produce large intrahepatic lesions with interstitial laser coagulation Br. J. Surg. 1245-8

[36] Patterson E J, Scudamore C H, Eng E, Owen D A, Nagy A G and Buczkowski A K 1998 Radiofrequency Ablation of Porcine Liver In Vivo Effects of Blood Flow and Treatment Time on Lesion Size Ann. Surg. 227 559-65

[37] Dorr L N and Hynynen K 1992 The effects of tissue heterogeneities and large blood 
vessels on the thermal exposure induced by short high-power ultrasound pulses Int. J. Hyperth. 8 45-59

490

491

492

493

494

495

496

497

498

499

500

501

502

503

504

505

506

507

508

509

510

511

512

513

514

515

[38] Chato J . 1985 Measurement of thermal properties of biological materials Heat Transf. Med. Biol. 1 167-92

[39] Valvano J W, Cochran J R and Diller K R 1985 Thermal Conductivity and Diffusivity of Biomaterials Measured with Self-Heated Thermistors Int. J. Thermophys. 6 301-11

[40] Valvano J . and Chitsabesan B 1987 Thermal conductivity and diffusivity of arterial wall and atherosclerotic plaque Lasers Life Sci. 1219-29

[41] Gammell P M, Le Croissette D H and Heyser R C 1979 Temperature and frequency dependence of ultrasonic attenuation in selected tissues Ultrasound Med. Biol 5 26977

[42] Damianou C A, Sanghvi N T, Fry F J and Maass-Moreno R 1997 Dependence of ultrasonic attenuation and absorption in dog soft tissues on temperature and thermal dose J. Acoust. Soc. Am. 102 628-34

[43] Gertner M R, Wilson B C and Sherar M D 1997 Ultrasound properties of liver tissue during heating Ultrasound Med. Biol. 23 1395-403

[44] Techavipoo U, Varghese T, Zagzebski J A, Stiles T and Frank G 2002 Temperature Dependence of Ultrasonic Propagation Speed and Attenuation in Canine Tissue Ultrason. Imaging 24 246-60

[45] Zderic V, Keshavarzi A, Andrew M A, Vaezy S and Martin R W 2004 Attenuation of porcine tissues in vivo after high-intensity ultrasound treatment Ultrasound Med. Biol. $3061-6$

[46] Choi M J, Guntur S R, Lee J M, Paeng D G, Lee K I L and Coleman A 2011 Changes in ultrasonic properties of liver tissue in vitro during heating-cooling cycle concomitant with thermal coagulation Ultrasound Med. Biol. 37 2000-12

[47] Ghoshal G, Luchies A C, Blue J P and Oelze M L 2011 Temperature dependent ultrasonic characterization of biological media J. Acoust. Soc. Am. 130 2203-11

[48] Jackson E, Coussios C and Cleveland R 2014 Nonlinear acoustic properties of ex 
vivo bovine liver and the effects of temperature and denaturation Phys. Med. Biol 59 3223

518

[49] Bamber, J.C Hill C . 1979 Ultrasonic attenuation and propagation sped in mammalian tissues as a function of temperature Ultrasound Med. Biol. 5 149-57

[50] Constans C, Mateo P ., Tanter M and Aubry J . 2018 Potential impact of thermal effects during ultrasonic neurostimulation: retrospective numerical estimation of temperature elevation in seven rodent setups Phys. Med. Biol. 63

[51] Eikelder H H ten; Bosnacki D D, Elevelt A, Donato K, Tullio A D, Breuer B B, Wijk J van;, Dijk E E van;, Modena D, Yeo S S Y and Grüll H H 2016 Modelling the temperature evolution of bone under high intensity focused ultrasound Phys. Med. Biol. 61

[52] Pinton G, Aubry J-F, Fink M and Tanter M 2011 Effects of nonlinear ultrasound propagation on high intensity brain therapy Med. Phys. 38 1207-16

[53] Meaney P M, Clarke R L, Ter Haar G R and Rivens I H 1998 A 3-D finite-element model for computation of temperature profiles and regions of thermal damage during focused ultrasound surgery exposures Ultrasound Med. Biol. 24 1489-99

[54] Fujiwara R, Sasaki K, Ishikawa T, Suzuki M, Umemura S-I, Kushima M and Okai T 2002 Arterial Blood Flow Occlusion by High Intensity Focused Ultrasound and Histologic Evaluation of Its Effect on Arteries and Surrounding Tissues $J$ Med Ultrason. 29 85-90

[55] Hwang J H, Zhou Y, Warren C, Brayman A A and Crum L A 2010 Targeted venous occlusion using pulsed high-intensity focused ultrasound IEEE Trans Biomed Eng $\mathbf{5 7}$ $37-40$

[56] Loffroy R, Guiu B, Cercueil J-P and Krause D 2009 Endovascular Therapeutic Embolisation: An Overview of Occluding Agents and their Effects on Embolised Tissues Curr. Vasc. Pharmacol. 7 250-63

[57] Hynynen K, Colucci V, Chung A and Jolesz F 1996 Noninvasive arterial occlusion using MRI-guided focused ultrasound Ultrasound Med. Biol 22 1071-7 
